\title{
EFFECTS OF VASODILATORS ON MICROCIRCULATION OF THE RAT CREMASTER MUSCLE: A MICROSCOPIC METHOD FOR SCREENING DRUGS
}

\author{
Matao SAKANASHI and Ichiya HIRAKI \\ Department of Pharmacology, Kumamoto University Medical School, \\ Kumamoto 860, Japan
}

Accepted August 28, 1978

\begin{abstract}
Effects of vasodilating drugs on microcirculation of the rat cremaster muscle were investigated microscopically. Topical application and intravenous injection of papaverine produced dilatation of arterioles. Cyclandelate applied topically dilated the arterioles to a considerable extent. Topical application of bamethan induced arteriolar dilatation while bamethan given intravenously constricted the arterioles. Kallikrein applied topically induced a slight dilatation of arterioles, and intravenous administration of kallikrein produced an apprcciable vasodilatation. Topical administration of bradykinin produced a vasodilatation of arterioles of the rat cremaster muscle. These results indicate that direct action of a drug on the microcirculation can be properly cvaluated by the microscopic method in the rat cremaster muscle, if the drug is applied topically, in the vicinity of small vessels under study.
\end{abstract}

Most pharmacological studies on the action of vasoacting substances have been done hemodynamically or using an isolated organ. We attempted to acquire pertinent information by observing visually the effects on a living body. Grant (1) and Majno et al. (2) proposed that the vasculature of the rat cremaster muscle is an appropriate model for the purpose of observing microcirculation in the striated muscle in vivo. The histological structure of the rat cremaster muscle is similar to one of the skeletal muscles of the extremeties, and the vasculature of the cremaster is innervated by the sympathetic nerve $(1,3)$. By removing only the fascia of the cremaster muscle, the microcirculation can be easily observed without complicated manipulations.

In the present cxperiments we directly observed the microcirculation of the rat cremaster using an optical microscope and investigated the effects of some vasodilating agents.

\section{MATERIALS AND METHODS}

Sixty-five male Wistar rats weighing $100-180 \mathrm{~g}$ were anesthetized with pentobarbital sodium $50 \mathrm{mg} / \mathrm{kg}$ i.p. and put on a warm pad maintained at $36^{\circ} \mathrm{C}$ by a heater. The exposure of the microvasculature of the cremaster muscle was similar to that reported previously $(4,5)$. The abdomen was opened transversely about $1.0 \mathrm{~cm}$ at about $1.0 \mathrm{~cm}$ below the xiphoid. A glass fiber rod of $8 \mathrm{~mm}$ diameter was inserted into the left scrotum and light was conducted from a lamp (Olympus, GB-4). The skin of the left groin was cut about $5 \mathrm{~mm}$ laterally to the penis, and most of the fascia covering the cremaster was removed. The edge of the skin was then raised with hooks so that it could hold a pool of about $0.3 \mathrm{ml}$ of 
a physiological saline solution over the exposed cremaster. The microcirculation of the cremaster was observed under an optical microscope (Shimazu, SKD-3) and photographed with an Olympus, PF-6 camera. Animals with spontaneous movements of skeletal muscle were immobilized with succinylcholine chloride $1.0 \mathrm{mg} / \mathrm{kg}$ i.v. and ventilated with a positive pressure artificial respirator (Harvard, 661). Drugs were applied topically or intravenously. Topical applications of drug solutions were given in a volume of $0.03 \mathrm{ml}$ into a pool over the exposed cremaster. The concentrations used represented those of drug solutions applied topically, and were expressed as $\mathrm{g} / \mathrm{ml}$ of salts. When applied, the solutions were warmed to $36^{\circ} \mathrm{C}$ to prevent any change in temperature. Drugs injected intravenously were given in terms of $\mathrm{mg} / \mathrm{kg}$ of the salts. In rats, which had been given an intravenous injection of drugs, the hemodynamic performance was monitored. Arterial blood pressure was measured with an elcetronic manometer (Nihonkoden, MP-4T) through a polyethylene tube inserted into the right common carotid artery. Heart rate was counted by a tachometer (Nihonkoden, RT-5) triggered with an electrocardiogram (Lead II). Changes in each parameter were recorded on an ink-writing polygraph (Nihonkoden, RM-150).

Drugs employed included dl-norepinephrine hydrochloride (Sankyo), dl-isoproterenol hydrochloride (Nikken-Kagaku), acetylcholine chloride (Daiichi), papaverine hydrochloride (Dainippon), cyclandelate (Takeda), bamethan sulfate (Vasculat ${ }^{\circledR}$, C.H. Boeringer), kallikrein (Bayer), bradykinin (Sandoz), succinylcholine chloride (Yamanouchi) and pentobarbital sodium (Tanabe). All drugs were dissolved in physiological saline. Measurement of diameter of the vessels on photographs was done by mcans of slide calipers. The effects of drugs were presented as percent changes of the control diameter. Wc used five preparations per one drug treatment. Student's $t$-test was used to determine the statistical significance.

RESULTS

\section{Effects of autonomic dirgs}

Topical application of both acetylcholine $10^{-5} \mathrm{~g} / \mathrm{ml}$ and isoproterenol $10^{-5} \mathrm{~g} / \mathrm{ml}$ resulted in at dilated arterioles. Maximal effects reached $126 \pm-9 \%$ of the control value (means $-\mathrm{SE}$, $\mathrm{n}=5, \mathrm{P}<0.05$, Table 1) $3 \mathrm{~min}$ after application of acetylcholine and $162 \pm 21 \%(\mathrm{n}=5$, $\mathrm{P}<0.05$, Table 1) 7 min after isoproterenol, respectively. On the other hand, isoproterenol $0.005 \mathrm{mg} / \mathrm{kg}$ i.v. constricted the arterioles $30 \mathrm{sec}$ after administration as shown in Fig. 1, and the arteriolar diameter was $55.15 \%(\mathrm{n}=5, \mathrm{P}<0.05$, Table 1$)$. Changes in microcirculation by norepinephrine $10^{-7} \mathrm{~g} / \mathrm{ml}$ began $30 \mathrm{sec}$ after topical application, and $2 \mathrm{~min}$ after, the arterioles were constricted $1011-.5 \%$ of the control diameter $(\mathrm{n}=5, \mathrm{P}<0.001$, Table 1). At this time the erythrocytes could be observed. Norepinephrine $0.002 \mathrm{mg} / \mathrm{kg}$ i.v. produced similar effects to topical application on the eremaster circulation. The diameter reached $7 \pm 3 \%$ of the control value $(n=5, P<0.001$, Table 1$)$.

Hemodynamic changes by intravenous administration of isoproterenol and norepinephrine are shown in Table 2. Arterial blood pressure fell to $83 \doteq 5 \mathrm{mmHg}(\mathrm{n}=5, \mathrm{P}<0.05)$ from the control pressure $(110 \pm 9 \mathrm{mmHg})$ after injection of isoproterenol $0.005 \mathrm{mg} / \mathrm{kg}$, and 

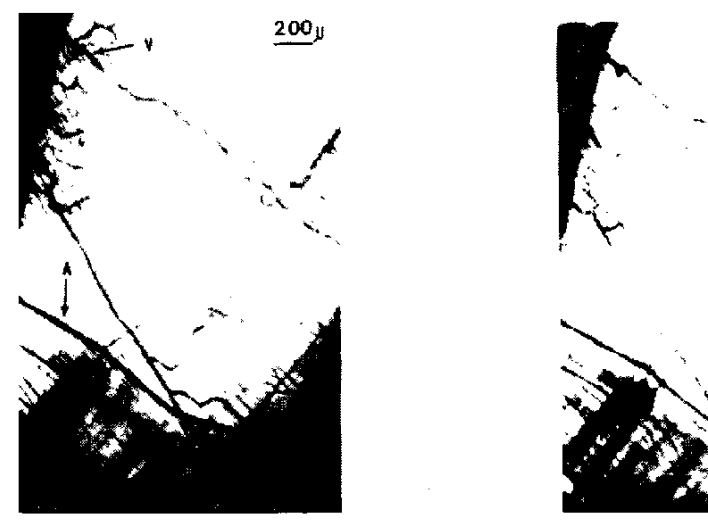

FIG. 1. Effect of isoproterenol $0.005 \mathrm{mg} / \mathrm{kg}$ i.v. left panel; control. right panel; $30 \mathrm{sec}$ after injection. A; arteriole. $V$; venule.

TABLE 1. Relative changes in diameter of arterioles of rat cremaster muscle in terms of untreated vessel diameter $=100 \%$.

\begin{tabular}{lcc}
\hline & Topical & Intravenous \\
Acetylcholine & $126 \pm 9^{*}$ & - \\
Isoprotcrenol & $162 \pm 21^{*}$ & $55 \pm 15^{*}$ \\
Norepinephrine & $11+5^{* *}$ & $7 \pm 3^{* *}$ \\
Papaverine & $127 \pm 8^{*}$ & $138 \pm 12^{*}$ \\
Cyclandelate & $288-52^{*}$ & - \\
Bamcthan & $158 \ldots 20^{*}$ & $38 \pm 18^{*}$ \\
Kallikrcin & $107 \pm 6$ & $147 \pm 15^{*}$ \\
Bradykinin & $139-14^{*}$ & - \\
\hline
\end{tabular}

Each value represents means + SE for 5 experiments. Values are signficantly different from respective control values, ${ }^{*} \mathrm{P}<0.05$ and $* \mathrm{P}<0.001$.

elevated to $147 \pm 8 \mathrm{mmHg}(\mathrm{n}-5, \mathrm{P}<0.01)$ from the control $(111=7 \mathrm{mmHg})$ after norepinephrine $0.002 \mathrm{mg} / \mathrm{kg} \mathrm{i.v}$. Heart rate increased to $454 \div 20$ beats $/ \mathrm{min}(\mathrm{n}=5$, NS) from $4 \mathrm{l} 3=17$ beats $/ \mathrm{min}$, and decreased to $392 \pm 12$ beats $/ \mathrm{min}(\mathrm{n}=5, \mathrm{NS})$ from $421 \pm 15$ beats $/ \mathrm{min}$, respectively.

\section{Effects of vasodilating drugs}

Effects of papaverine $20 \mathrm{mg} / \mathrm{kg}$ i.v. began $30 \mathrm{sec}$ after injection, and a significant dilatation of arterioles was observed about $50 \mathrm{sec}$ after (Fig. 2). The diameter of arterioles reached $138 \pm 12 \%$ of the control value $(n=5, P<0.05$, Table 1$)$. Topical application of papaverine $10^{-4} \mathrm{~g} / \mathrm{ml}$ also dilated the arterioles to $127=8 \%$ of the control $(\mathrm{n}-5, \mathrm{P}<0.05$, Table 1). Cyclandelate $1.5 \times 10^{-4} \mathrm{~g} / \mathrm{ml}$ applied topically produced a striking dilatation of arterioles of the cremaster 3 min after (Fig. 3), and the degree of dilatation was $288-52 \%$ ( $n=5, P<0.05$ ) as compared to the control (Table 1 ).

Three min after topical application of bamethan $10^{-5} \mathrm{~g} / \mathrm{ml}$, the arterioles were dilated to $158+20 \%$ of the control diameter $(n=5, P<0.05$, Fig, 4 and Table 1$)$. Intravenous 
administration of bamethan $0.5 \mathrm{mg} / \mathrm{kg}$ constricted the arterioles $1 \mathrm{~min}$ after (Fig. 5). The peak contraction of arterioles reached $38-18 \%(\mathrm{n}=5, \mathrm{P}<0.05$, Table 1). Thereafter, the vascular diameter recovered to the control level $10 \mathrm{~min}$ after.
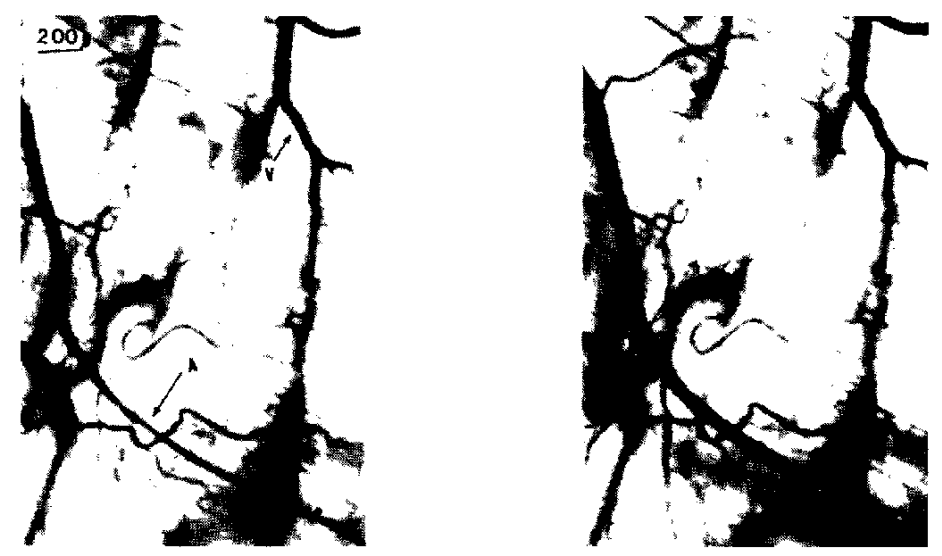

Fig. 2. Effect of papaverine $20 \mathrm{mg} / \mathrm{kg}$ i.v. left panel; control. right pancl: $50 \mathrm{scc}$ after injection. Abbreviations are as in Fig. 1.
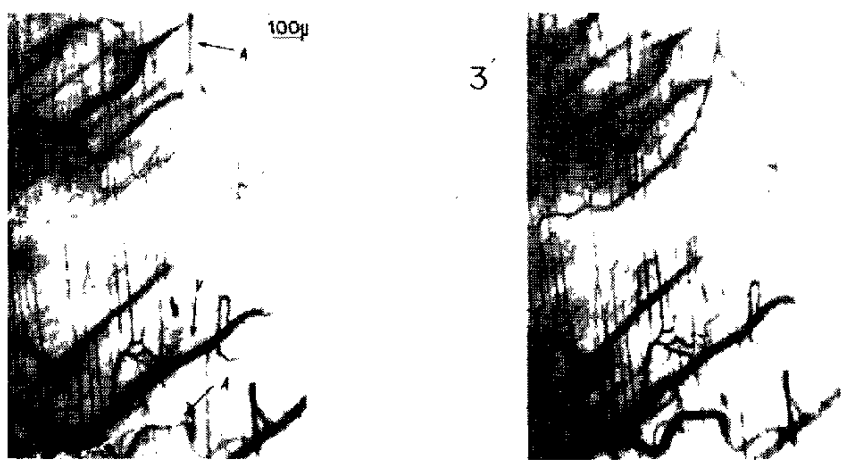

Fig. 3. Effect of cyclandelate $1.5 \times 10^{4} \mathrm{~g} / \mathrm{ml}$ applied topically. left panel; control. right panel: 3 min after application. Abbreviations are as in Fig. 1.
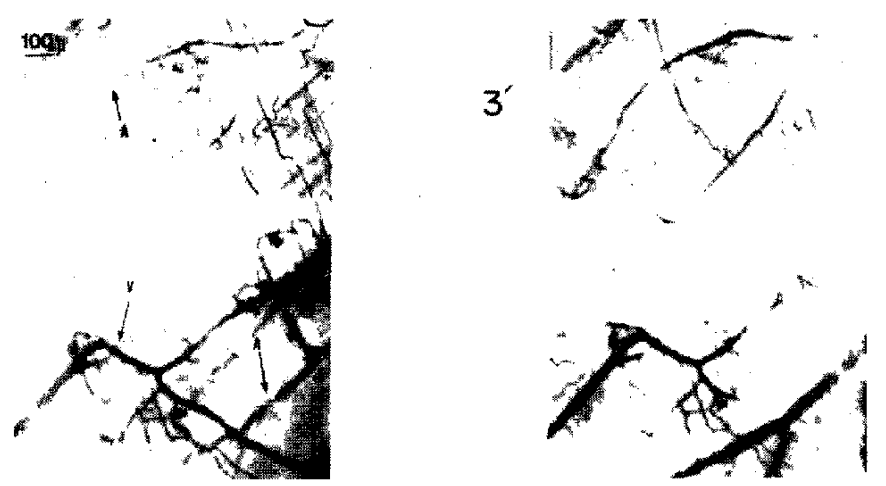

FiG. 4. Effect of bamethan $10^{-5} \mathrm{~g} / \mathrm{ml}$ applied topically, left panel; control. right panel; 3 min after application. Abbreviations are as in Fig. 1. 

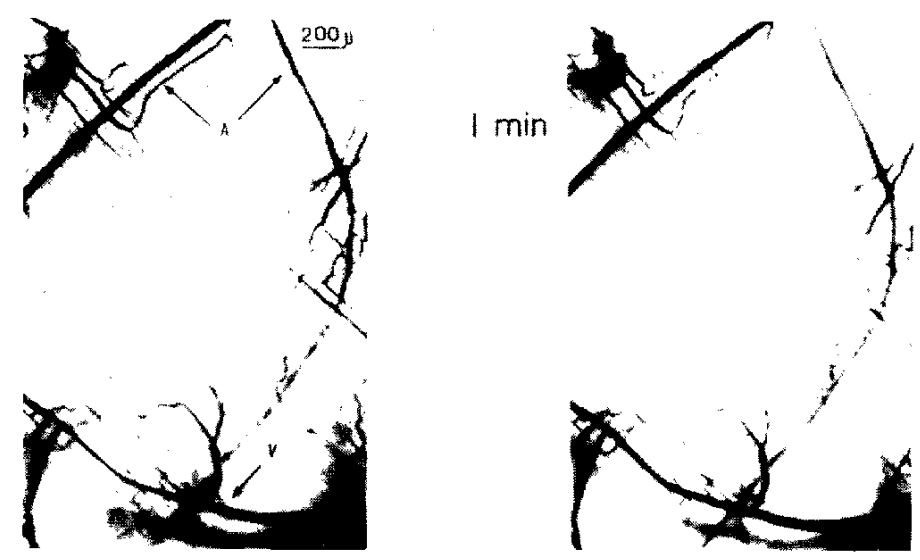

FiG. 5. Effect of bamethan $0.5 \mathrm{mg} / \mathrm{kg}$ i.v. left panel; control. right panel; $1 \mathrm{~min}$ after injection. Abbreviations are as in Fig. 1.

TABL.E. 2. Henodynamic effects of each drug i.v.

\begin{tabular}{lcccc}
\hline & \multicolumn{2}{c}{ BP $(\mathrm{mmHg})$} & \multicolumn{2}{c}{ HR (beats/min) } \\
& Control & After injection & Control & After injection \\
Isoproterenol $0.005 \mathrm{mg} / \mathrm{kg}$ & $110 \pm 9$ & $83 ! 5^{*}$ & $413 \cdots 17$ & $454 \div 20$ \\
Norepinephrine $0.002 \mathrm{mg} / \mathrm{kg}$ & $111 \div 7$ & $147+8^{* *}$ & $421-15$ & 392.12 \\
Papaverine $20 \mathrm{mg} / \mathrm{kg}$ & $101 \perp 6$ & $97-6$ & $452-23$ & $463+21$ \\
Bamethan $0.5 \mathrm{mg} / \mathrm{kg}$ & $127+10$ & $111-8$ & $438 ! 11$ & $458 \pm 13$ \\
Kallikrein $0.5 \mathrm{U} / \mathrm{kg}$ & $103 ! 7$ & $92+7$ & $435-33$ & $437+27$ \\
\hline
\end{tabular}

BP; arterial blood pressure. HR; heart rate. Each value represents means _- SE for 5 experiments. Values are significantly different from respective control values, ${ }^{*} \mathrm{P}, 0.05$ and $* P<0.01$.

Kallikrein $0.1 \mathrm{U} / \mathrm{ml}$ administered topically induced a slight dilatation $(107 \div 6 \%$ of the control, $\mathrm{n}=5$, NS, Table 1 ) of arterioles about 1 min after. When kallikrein $0.5 \mathrm{U} / \mathrm{kg}$ was given intravenously, a considerable arteriolar vasodilatation $(147 \div 15 \%, \mathrm{n}=5, \mathrm{P}<0.05)$ occurred $2 \mathrm{~min}$ after (Table 1). Bradykinin $10^{-5} \mathrm{~g} / \mathrm{ml}$ induced an appreciable dilatation of arterioles (139!14\% of the control diameter, $\mathrm{n}=5, \mathrm{P}<0.05) 4 \mathrm{~min}$ after topical application (Table 1). Intravenous administrations of papaverine $20 \mathrm{mg} / \mathrm{kg}$, bamethan $0.5 \mathrm{mg} / \mathrm{kg}$ and kallikrein $0.5 \mathrm{~L} / \mathrm{kg}$ produced a fall in arterial blood pressure and an increase in heart rate after injection of drugs, as shown in Table 2. Changes in these parameters were not statistically significant.

\section{DISCUSSION}

Acetylcholine and isoproterenol produce depressor effects on systemic blood pressure, while norepinephrine produces a pressor effect. The present results obtained by topical application of these drugs are consistent with the above hemodynamic observations, and indicate that the microcirculation of the rat cremaster muscle responds wcll to various drugs.

Papaverine and cyclandelate act directly on vascular smooth muscle $(6,7)$. In the 
present experiments both drugs produced a marked dilatation of arterioles.

Isoproterenol and bamethan are considered to produce vasodilatation through adrenergic beta-receptor activation. Indeed, isoproterenol and bamethan may act vasodilatively, since topical application of these drugs produced dilatation of arterioles of the rat cremaster. However, with i.v. administration of these two drugs, arteriolar vasoconstriction was observed. Grant (1) showed that adrenaline given i.v. caused arterial dilatation of the rat cremaster though this sympathomimetic constricted the artery when applied topically. Using the double thermistor method, Yamaura proposed that changes in cerebral blood flow are dependent on the systemic blood pressure (8). The fall of the systemic blood pressure induced by isoproterenol or bamethan given i.v. may be responsible for the arteriolar vasoconstriction of the rat cremaster. If isoproterenol and bamethan given i.v. do cause a relatively large arteriovenous anastomosis, these drugs should decrease the capillary blood flow resulting in an outward contraction of arterioles. However, in skeletal muscle, the existence of arteriovenous anastomosis has not been confirmed histologically (9), and no such anastomosis was evident in our experiment. Another possibility is that the hypotension induced by isoproterenol and bamethan given i.v. may produce a sympathetic reflex resulting in a vasoconstriction of the cremaster. In fact, tachycardia concomitant with hypotension was observed in this experiment when these drugs were applied intravenously. However, we were not able to identify the sympathetic reflex since both isoproterenol and bamethan evoked a tachycardia directly through an adrenergic beta-receptor activation.

In vivo kallikrein is converted to bradykinin by enzymatic reaction. Therefore, the action of kallikrein must be essentially consistent with that of bradykinin. In the present experiments, kallikrein given i.v. and the topical application of bradykinin induced an appreciable dilatation of arterioles in the cremaster muscle. This finding is similar to the report of Takenaka et al. (10) who found that the oxygen availability in the cremaster muscle increased polarographically and at the same time the cremaster microvasculature was seen to dilate. However, kallikrein applied topically cvoked no such dislinct effects on the microvasculature. This result suggests that kallikrein applied topically may be difficult to convert to bradykinin and/or the doses of kallikrein applicd may be too low.

As observed in the present experiments, topical applications of drugs showed the same results seen with hemodynamic investigations. On the other hand, intravenous administration of adrenergic beta-receptor stimulants, isoproterenol and bamethan, unexpectedly produced a vasoconstriction. Therefore, it is concluded that a topical application is more suitable than an intravenous injection for screening drugs when microscopic examinations are being carried out. Merits of the present microscopic method are as follows: (1) the microcirculation of the cremaster muscle can be simply and readily prepared; (2) the rat cremaster microcirculation responds well to various drugs applied topically; and (3) the experiments do not require a large scale apparatus. On the other hand, the demerit is that analysis of the data tends to be subjective; for example, the measurement of the arteriolar diameter may be affected by the degree of development and printing of the photographs. 


\section{REFERENCES}

1) Grant, R.T.: Direct observation of skeletal muscle blood vessels (rat cremaster). J. Physiol. 172, 123-137 (1964)

2) Majno, G., Gitmore, V. and Leventhal, M.: Technique for the microscopic study of blood vessels in Iiving striated muscle (cremaster). Circulation Res. 21, 823-832 (1967)

3) GRANT, R.T.: The effects of denervation on skeletal muscle blood vessels (rat cremaster). J. Anat. 100, 305-316 (1966)

4) Sakanash, M., Hiraki, I., Araki, H., Tomomatsu, E., Iwasaki, K. and Takenaka, F.: Effects of dihydrocrgotamine methanesulfonate on the microcirculation of the rat cremaster muscle. Arch. Pharmacol. 301, 83-85 (1977)

5) Hiraki, I.: Effects of some autonomic drugs and dihydroergotamine methanesulfonate on the microcirculation of rat cremaster muscle. J. Kumamoto med. Soc. 51, 312-319 (1977) (Abs, in English)

6) Ulki, S., Sugano, H., Iwaki, J., Sato, N., Howasili, T., Akiyama, T., Nomura, E., Fukuda, T. ANd Saknyoto, H.: A pharmacological study on cyclandelate. Folia pharmacol. japon. 61, 502-513 (1965) (Abs. in English)

7) Taklnaka, F., Takeya, N., Oka, K., Nasu, T., Murakoshi, Y., Sugiyama, M. and Yamada, T.: The cardiovascular actions of cyclandelate. Folia pharmacol. jupon. 61, 514-522 (1965) (Abs. in English)

8) Yamaura, A.: Regional blood flow of cerebral corlex in cat. J. Japan. Coll. Angiol. 10, 61-68 (1970) (Abs. in English)

9) Barlow, T.E., Haigh, A.L. and Watdfr, D.N.: A search for arteriovenous anastomoses in skclctal muscle. J. Phiysiol. 143, 80P-81P (1958)

10) Takenaka, F., Hiraki, I. ANd Mitsuflit, Y.: Effect of bencyclane on cerebral circulation in rabbit and cremaster muscle circulation in rat. Pharmacometrics 10, 85-92 (1975) (Abs, in English) 